\title{
Tertiary Syphilis in the Cervical Spine: A Case Report and Review of the Literature
}

\author{
K. M. I. Salem ${ }^{1} \quad$ H. Majeed ${ }^{1} \quad$ R. Bommireddy ${ }^{1} \quad$ Z. Klezl $^{1,2}$
}

${ }^{1}$ The Department of Trauma and Orthopaedic Surgery, Royal Derby Hospital, Derby, United Kingdom

2 Orthopedic Department of Third Medical School, Charles University, Prague, Czech Republic

\begin{abstract}
Address for correspondence Mr. Z. Klezl, M.D., Ph.D., The Department of Trauma and Orthopaedic Surgery, Royal Derby Hospital, Uttoxeter Road, Derby DE22 3NE, United Kingdom (e-mail: zklezl@aospine.org).
\end{abstract}

Global Spine J 2013;3:41-46.
Abstract
Keywords
- syphilis
- cervical
- spine
- tertiary syphilis

As the prevalence of syphilis rises, an increase in tertiary syphilis with spinal involvement is predicted. We report what we believe to be the first case of compressive cervical spine syphilitic gummata, with central cord compression signs. We also review the relevant literature to date. The diagnosis of syphilis in the spine relies on the physician to be aware of it as part of the differential diagnosis. Treponemal laboratory tests are an important aid in establishing a diagnosis.
The rate of infection with syphilis is increasing, with a recently reported 25-fold rise in homosexual men, a sixfold rise in heterosexual men, and a three-fold rise in women. ${ }^{1}$ Although tertiary syphilis is considered rare in the developed world, its prevalence has been increasing in the United States, the United Kingdom, Australia, and Europe. ${ }^{2}$ A similar trend has also been reported in China and Russia since the 1990s and has been attributed to unsafe sexual practice. ${ }^{2}$ Gummatous syphilis in the spine is very rare, although cases have been reported in the thoracic and lumbar spine. In this article, we present what we think to be the first reported case of gummatous syphilis in the cervical spine, presenting as a mass lesion with long tract signs. The relevant literature to date is also reviewed.

\section{Case Report}

An 82-year-old man presented to the emergency department, having woken with right hand numbness and significant difficulty walking. His only past medical history was hypertension and 3 years of chronic neck pain. No red flags for infection or malignancy were reported. On examination, he was not in any pain and was apyrexial. Neurologically, he had generalized weakness, with grade 3 power in both upper and lower limbs on the American Spinal Injury Association (ASIA) scale, and upper motor neuron signs were found bilaterally in

both upper and lower limbs (positive Hoffman's, a positive inverted radial reflex, and up-going plantar reflexes). His medical notes identified a positive Treponema pallidum hemagglutination (TPHA) test (titer 320) performed 8 years ago to exclude yaws disease, as part of the investigation of a chronic, slowly healing ulcer on his foot.

Laboratory investigations on admission showed mild anemia (hemoglobin $10.2 \mathrm{~g} / \mathrm{dL}$ ); normal white blood count $\left(6.7 \times 10^{3} / \mu \mathrm{L}\right)$, and raised C-reactive protein $(53 \mathrm{mg} / \mathrm{L})$. Whole spine magnetic resonance imaging (MRI) identified severe narrowing between the $\mathrm{C} 2-3$ and $\mathrm{C} 3-4$ discs. Radiologically, this appeared to be partly due to thickening of the posterior longitudinal ligament. However, the severe canal stenosis was felt to be acutely exacerbated by a posterior extradural collection deep to the lamina. Partial ankylosis of the C4-5 disc space was also noted (-Figs. 1A, 1B). A cervical spine CT scan was subsequently performed, which illustrated calcification in the soft tissues posterior to the cord corresponding with the stenotic area on MRI, suggesting a chronic process with subsequent calcification of the ligamentum flavum. The images also confirmed ankylosis across the C45 disc and facet joints bilaterally (-Fig. 2). The clinical picture was consistent with an extradural compressive lesion, and the possibility of gummatous tertiary syphilis in the cervical spine was disregarded. Cerebrospinal fluid analysis was therefore not performed.

(c) 2013 Georg Thieme Verlag KG Stuttgart · New York
DOI http://dx.doi.org/ $10.1055 / \mathrm{s}-0032-1329887$. ISSN 2192-5682. 

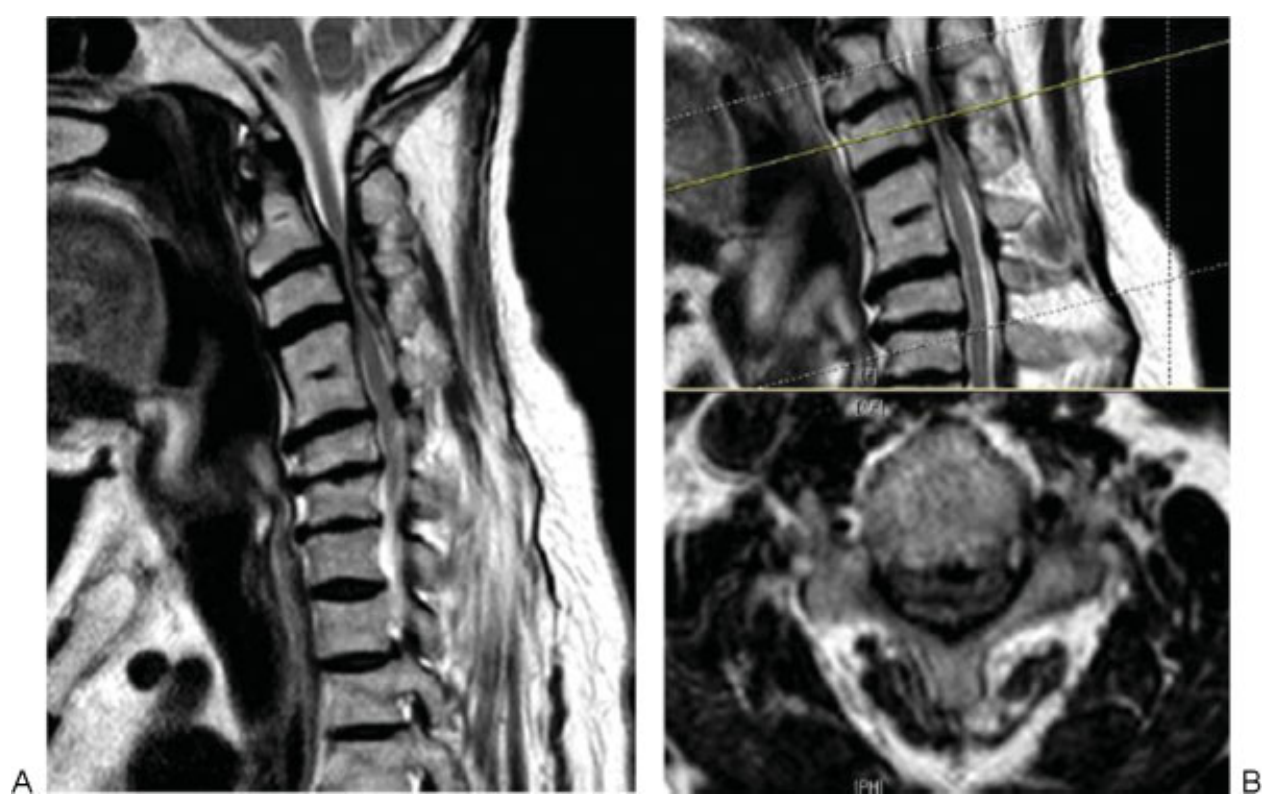

Figure 1 (A, B) Cervical spine magnetic resonance imaging showing severe central canal stenosis at C2-3 and C3-4 level with partial ankylosis of the $C 4-5$ disc space.

Three days following admission, the patient underwent a posterior C2-C5 decompression and instrumented fusion from C2 to C5 (-Fig. 3). Intraoperatively, an organized collection was found around the cord, at the level of the stenosis, with a partially calcified membrane covering the dural sac.

Samples were sent for culture and sensitivity, which grew no organisms in the aspirate or tissue culture, extended anaerobic culture, or the enrichment broth culture. Direct film for acid-alcohol-fast bacilli and tuberculosis culture were negative after 8 weeks' incubation. Histology showed chronically inflamed fibrous tissue and degenerate fibrocartilage, delineated by necrotic material, which enclosed calcific deposits and a small number of chondrocytes. No obvious caseating material or abscess contents were demonstrated.

A repeat of the nontreponemal and treponemal tests gave a positive Venereal Disease Research Laboratory (VDRL) slide test, a positive TPHA test (titer $>1280$ ), a positive syphilis immunoglobulin (Ig) G enzyme-linked immunoassay (ELISA) and a negative syphilis IgM ELISA. The results confirmed tertiary syphilis.

These findings were discussed with the microbiologist, and once-weekly benzathene penicillin G 2.4 million units

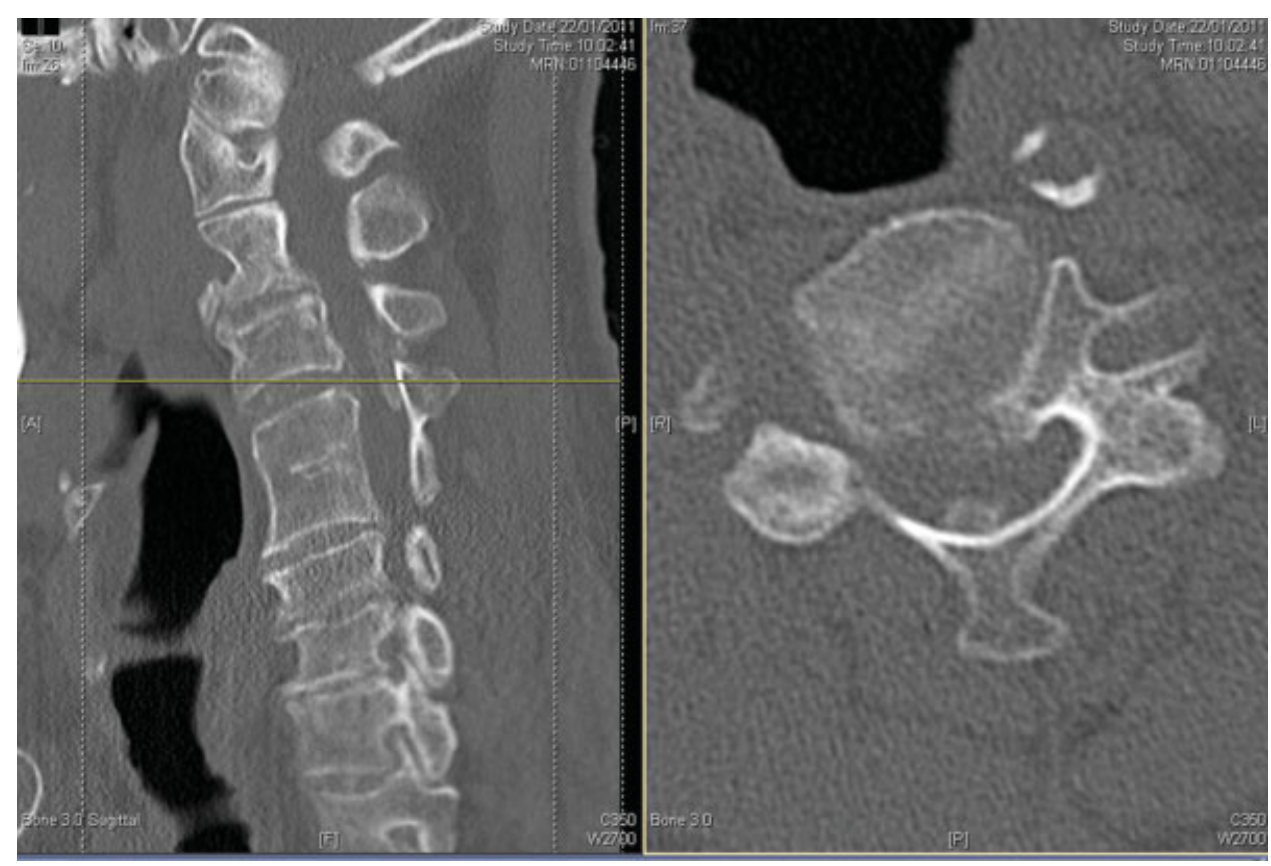

Figure 2 Cervical spine computed tomography scan showing calcification in the soft tissue mass posterior to the cord and in the ligamentum flavum. Images further detail the C4-5 ankylosis. 

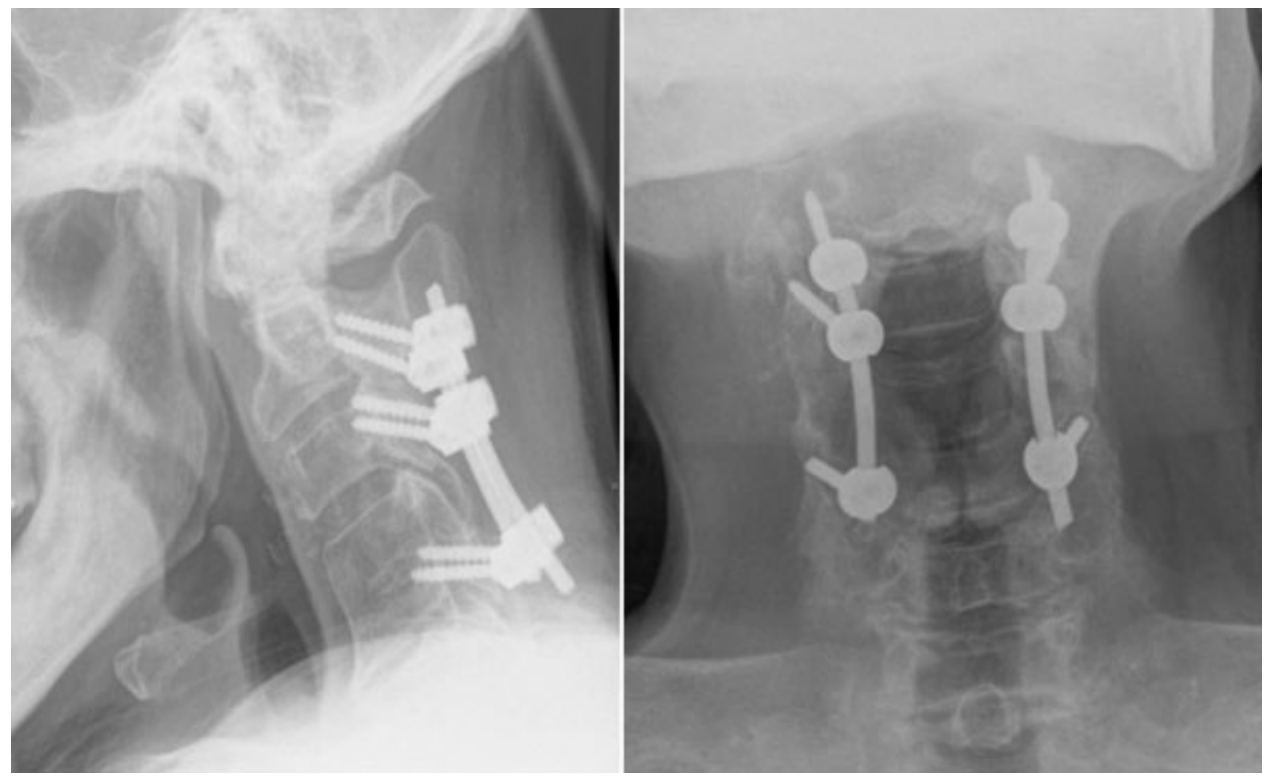

Figure 3 Postoperative X-rays of the cervical spine.

intramuscular injection was administered for 3 weeks. The patient was discharged home with outpatient physiotherapy and rehabilitation. A follow-up MRI scan at 1 year confirmed adequate decompression with no evidence of recurrence (-Fig. 4). Dynamic radiological evaluation showed the cervical spine to be stable ( - Fig. 5). He showed slow but progressive improvement and at 1 year, he was mobilizing with crutches and was able to carry out his usual daily activities with minimal difficulty. Neurologically, he had regained full power in his upper limbs (ASIA grade 5) and had nearly recovered fully in his lower limbs (ASIA grade $4+$ ). There was residual evidence of previous long tract involvement with persistent upper motor neuron signs.

\section{Discussion}

Syphilis is a bacterial infection caused by the spirochete Treponema pallidum. It is primarily a sexually transmitted
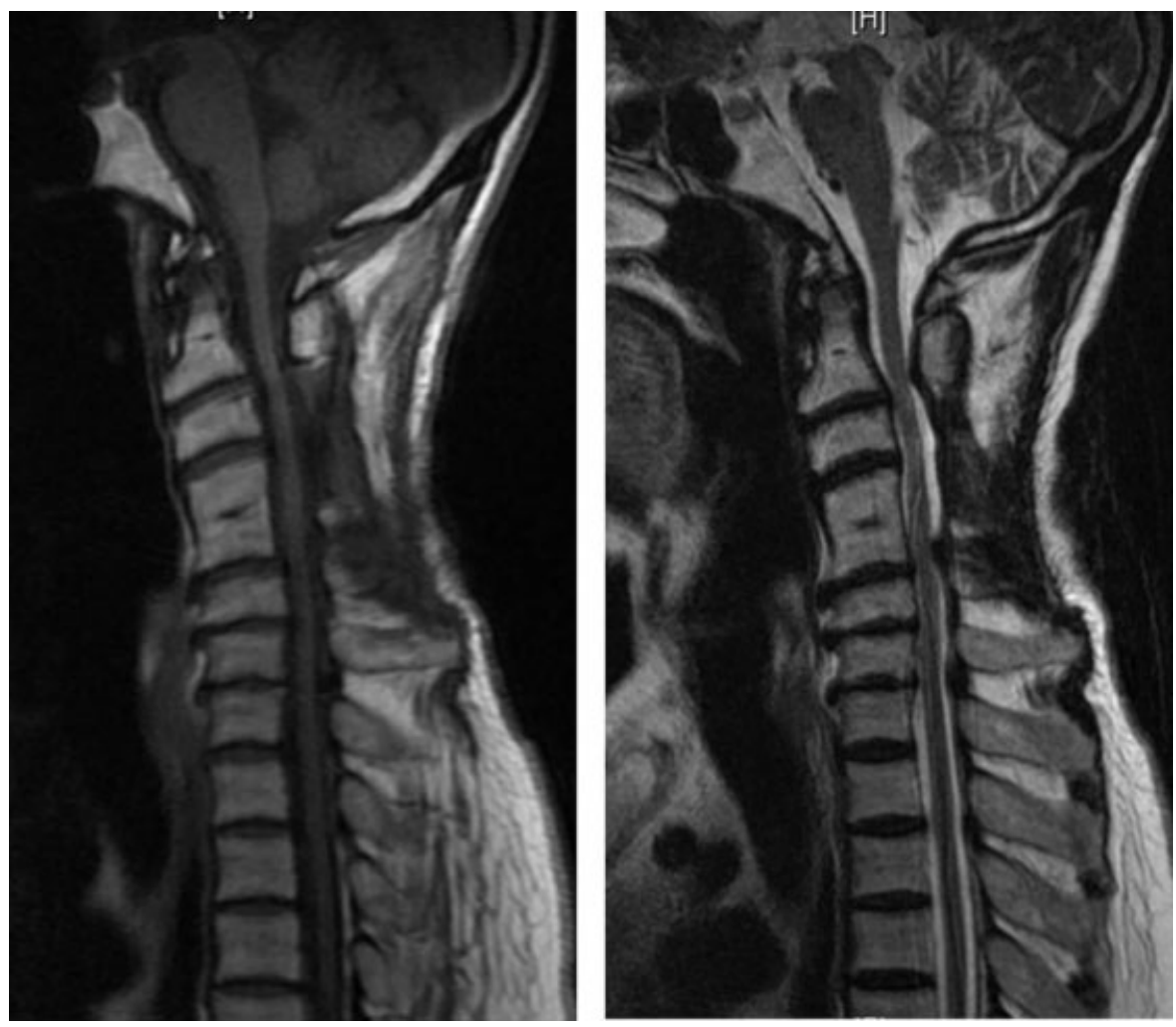

Figure 4 A follow-up magnetic resonance imaging scan at 1 year showing adequate cervical cord decompression with no evidence of recurrence. 

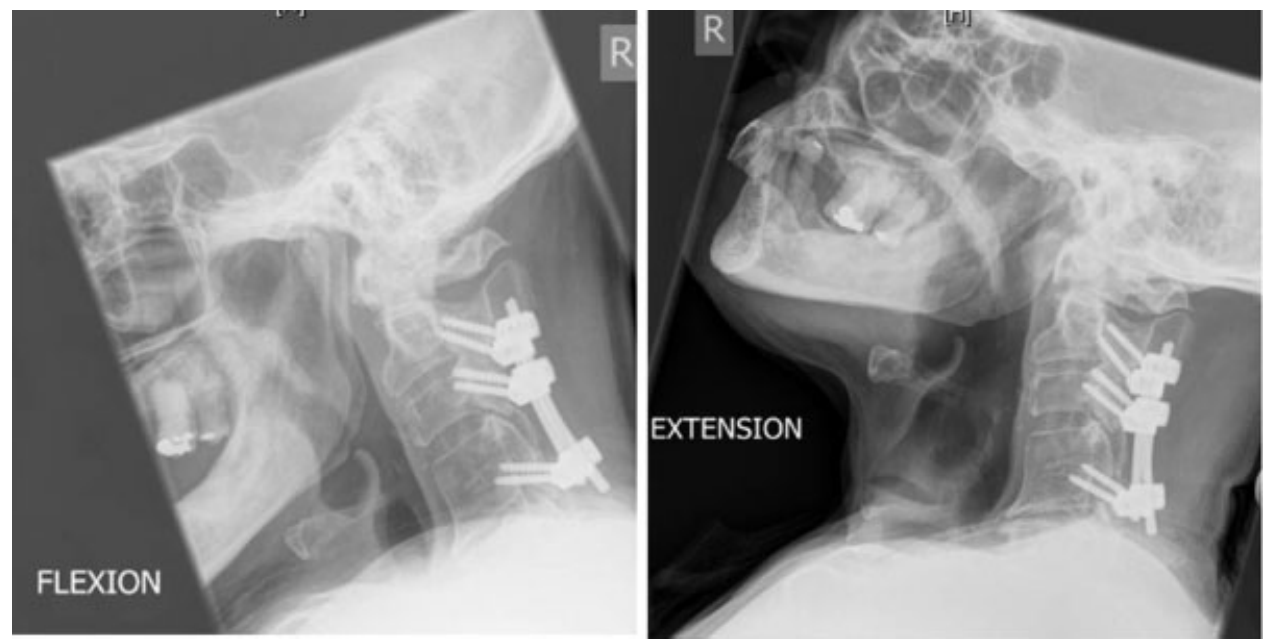

Figure 5 Dynamic radiological image confirming cervical spine stability.

infection with a single exposure infection risk of $\sim 30 \%$ (range, 10 to $80 \%)^{3,4}$ It can also be transmitted to the fetus during pregnancy or birth leading to the congenital form of the disease, which carries a high mortality rate (up to $50 \%$ ). ${ }^{5}$ The spirochete subspecies that causes syphilis is called pallidum, but other clinical presentations such as yaws or pinta have been reported with treponemal infections from other subspecies such as pertenue and carateum. According to the World Health Organization (WHO), 12 million new cases of syphilis occur every year with an estimated $90 \%$ of these cases occurring in developing countries. ${ }^{6}$

Despite the elusive nature of the condition (nicknamed "the great imitator"), ${ }^{2}$ four disease stages have been identified. The primary stage is characterized by a chancre associated with regional lymphadenopathy. The incubation period is 9 to 90 days. The chancre is usually a single painless ulcer, classically in the anogenital region, with a clean base and clear discharge. However, chancres may be multiple, painful, purulent, and extragenital (mostly oral). The secondary stage usually occurs within the first 2 years of infection. The rash of secondary syphilis is generally not itchy and is often associated with mucocutaneous lesions, generalized lymphadenopathy, and multisystem involvement (anterior uveitis, meningitis, cranial nerve palsies, hepatitis, splenomegaly, periostitis, and glomerulonephritis)..$^{4,7}$ The latent stage is characterized by positive disease serology without symptoms. The final stage is tertiary syphilis, which affects a third of those infected, 3 to 15 years after the initial exposure, and may be further subdivided into three different forms: gummatous syphilis (15\%), late neurosyphilis (6.5\%), and cardiovascular syphilis $(10 \%)^{2}$

Gummatous syphilis is characterized by soft, tumor-like inflammatory destructive lesions of varying sizes that may occur anywhere in the body but most commonly affect the skin and bone. ${ }^{8}$ Cardiovascular syphilis may take the form of aortitis with secondary aneurysmal dilatation, aortic regurgitation, cardiac ischemia, and failure.

Cerebrospinal fluid abnormalities have been identified in both the primary and secondary stages of the disease in up to
$30 \%$ of patients. They do not serve as an indicator for the subsequent development of neurosyphilis when identified in the early stages. ${ }^{8,9}$

Central nervous system pathology can be mesoblastic (interstitial) or parenchymatous. The mesoblastic form can be further subdivided into endarteritis, meningitis, and gummatous with secondary infarctions and meningeal inflammation. The parenchymatous form can be focal or diffuse, cerebral or cerebellar or tabitic (dorsal column demyelination) based on the anatomic location of the lesion. This results in a very variable clinical picture that may include general paresis, memory and cognitive deterioration, psychosis, dementia, localized paresis, and occasionally seizures. The term tabes dorsalis describes spinal dorsal column involvement that results in neuropathic ulceration, joint disorganization, and sensory ataxia secondary to the involvement of the dorsal spinal column.

Syphilis can simulate other granulomatous diseases such as tuberculosis. This makes it very difficult to confirm the diagnosis with histology and imaging. Syphilis can be confirmed by identifying its causative microorganism using dark ground microscopy or serological testing with the latter being the gold standard investigation. ${ }^{10} \mathrm{~T}$. pallidum does not produce exotoxins but is capable of inducing a host immune response resulting in the symptoms described earlier. This is the result of two types of antibodies: a nonspecific type that targets the microorganism's structural phospholipid content (nontreponemal antibodies) and a second type (treponemal antibodies) that target the T. pallidum polypeptides. ${ }^{4}$ Traditionally, syphilis has been diagnosed using a nontreponemal screening test. However, as these tests occasionally give a false-positive result, confirmation is required using treponemal serological tests. ${ }^{11}$ The nontreponemal antibodies are detected using the rapid plasma reagin (RPR) test, the VDRL test, and the toluidine red unheated serum test. Treponemal antibodies are detected by immunofluorescence in the fluorescent treponemal antibody-absorbed (FTA-ABS) test or by agglutination in the TPHA or T. pallidum particle agglutination test. $2,4,5,11$ 
The clinical diagnosis of neurosyphilis is based on identifying symptoms and signs of meningitis, visual or hearing disturbance, or sensory or motor deficit associated with cerebrospinal fluid (CSF) abnormalities such as high white blood cell count ( $>5$ cells $/ \mathrm{mm}^{3}$ ), high protein, or a positive CSF VDRL test. If CSF testing is negative, neurosyphilis can be excluded. ${ }^{4,8}$ As with other sexually transmitted diseases, if syphilis is identified, the patient should be screened for other sexually transmitted infections including HIV and their partners should be notified to reduce onward transmission.

\section{The Medical Treatment of Syphilis}

T. pallidum remains sensitive to penicillin with no reported cases of resistance. The slow division rate of the microorganism requires therapeutic antimicrobial blood levels for at least 7 days to cover multiple division cycles. ${ }^{8}$ The U.K. national guidelines on the management of syphilis recommend intramuscular benzathine penicillin as first-line treatment of the disease with penicillin serum concentrations in excess of $0.03 \mathrm{mg} / \mathrm{mL}$ for at least 7 days. This can be achieved using a single intramuscular injection of benzathine penicillin, which provides a therapeutic blood concentration for 2 to 3 weeks and eliminates difficulties with compliance attached to regimens of daily injections with procaine penicillin. A longer treatment course (30 days) is required for late syphilis as the microorganism division slows further and the penetration of benzathine penicillin across the blood-brain barrier is poor. ${ }^{7,8}$ - Table 1 outlines the most recent antimicrobial treatment guidelines for syphilis.

\section{Syphilis in the Spine}

Today, it is very uncommon for patients to present with tertiary syphilis. In 1950 , as many as $1.1 \%$ of the partially treated cases of syphilis progressed to a tertiary stage. ${ }^{12}$ Despite flaws in the methodology, the Oslo study (1955) reported benign tertiary syphilis in $15.8 \%$ of 1147 patients with untreated syphilis, mainly affecting the skin and mucous membranes. Skeletal lesions were prevalent in $9.6 \%$ of all cases. $^{13,14}$ Thus, syphilis affecting the skeleton can be expected in $\sim 1.5 \%$ of patients with untreated syphilis.

The prevalence of tertiary syphilis in the spine is not clear. $^{10,15,16}$ In the early 1970 s, Johns reported on two cases with syphilitic Charcot arthropathy in the spine. ${ }^{15} \mathrm{He}$ demonstrated the difficulty in establishing the diagnosis (particularly in the absence of the advanced serological testing available today) and reiterated the predilection of the Charcot arthropathy for the most mobile segments of the spine, namely the thoracolumbar and upper lumbar spine. These lesions are often asymptomatic but may be destructive, leading to nerve root involvement if hypertrophic changes are severe. ${ }^{16}$ Radiologically, the appearance of the lesions can be misleading and resemble an infective, inflammatory, or a neoplastic picture. Abnormal findings on radiographs include subchondral sclerosis, osteophytosis, subluxation, and soft tissue swelling. Long-standing neuroarthropathy is characterized by joint disorganisation. ${ }^{17}$ The exact pathophysiology of such changes is not clear. Two theories have been proposed: a neurotraumatic theory, suggesting the destructive joint process is the result of repeated trauma to the insensate joint, and a neurovascular theory, which proposes that hyperemia, secondary to autonomic neuropathy, leads to osteopenia due to a mismatch between bone synthesis and breakdown. Most likely the Charcot changes are the result of a combination of both.

More recently, a retrospective review of 24 patients diagnosed radiologically and serologically with tabetic arthropathy in Morocco reported a similar trend of lumbar spine involvement in $8 \%$ of cases with a high tendency for arthropathy in the large joints of the lower limb. ${ }^{18} \mathrm{~A}$ welldocumented history of primary syphilis was confirmed in

Table 1 Antimicrobial Treatment Recommendations for Syphilis, with Alternative Regimens Suggested for Patients Who Have a Penicillin Allergy or Refuse Parenteral Treatment

\begin{tabular}{|c|c|c|}
\hline Disease Stage & Recommended Treatment & Alternative Regimens \\
\hline $\begin{array}{l}\text { Incubating syphilis/ } \\
\text { epidemiological treatment }\end{array}$ & $\begin{array}{l}\text { Benzathine penicillin G } 2.4 \mathrm{MU} \\
\text { intramuscular single dose }\end{array}$ & $\begin{array}{l}\text { Doxycycline } 100 \text { mg PO twice daily for } 14 \text { days; } \\
\text { azithromycin } 1 \mathrm{~g} \text { PO single dose }\end{array}$ \\
\hline $\begin{array}{l}\text { Early syphilis (primary, } \\
\text { secondary, and early latent) }\end{array}$ & $\begin{array}{l}\text { Benzathine penicillin G } 2.4 \mathrm{MU} \\
\text { intramuscular single dose; procaine } \\
\text { penicillin G } 600,000 \mathrm{U} \text { daily } \\
\text { intramuscular injections for } 10 \mathrm{~d}\end{array}$ & $\begin{array}{l}\text { Doxycycline } 100 \text { mg PO twice daily for } 14 \text { d; } \\
\text { azithromycin } 2 \text { g PO single dose; azithromycin } \\
500 \text { mg PO daily } 10 \text { d; erythromycin } 500 \text { mg PO four } \\
\text { times daily for } 14 \text { d }\end{array}$ \\
\hline $\begin{array}{l}\text { Late latent, cardiovascular, and } \\
\text { gummatous syphilis }\end{array}$ & $\begin{array}{l}\text { Benzathine penicillin G } 2.4 \mathrm{MU} \\
\text { intramuscular injection weekly (three } \\
\text { doses); procaine penicillin G } 600,000 \\
\text { units daily intramuscular injections for } \\
17 \mathrm{~d}\end{array}$ & $\begin{array}{l}\text { Doxycycline } 100 \text { mg PO twice daily for } 28 \mathrm{~d} \text {; } \\
\text { amoxicillin } 2 \text { g PO three times daily plus probenecid } \\
500 \mathrm{mg} \text { four times daily for } 28 \mathrm{~d}\end{array}$ \\
\hline $\begin{array}{l}\text { Neurosyphilis including } \\
\text { neurological/ophthalmic } \\
\text { involvement in early syphilis }\end{array}$ & $\begin{array}{l}\text { Procaine penicillin } 1.8-2.4 \mathrm{MU} \\
\text { intramuscular once daily plus } \\
\text { probenecid } 500 \text { mg PO four times daily } \\
\text { for } 17 \text { days; benzylpenicillin } 18-24 \mathrm{MU} \\
\text { daily divided four hourly as a } 3-4 \mathrm{MU} \\
\text { intramuscular injection for } 17 \mathrm{~d}\end{array}$ & $\begin{array}{l}\text { Doxycycline } 200 \mathrm{mg} \text { PO twice daily for } 28 \mathrm{~d} \text {; } \\
\text { amoxicillin } 2 \mathrm{~g} \text { PO three times daily plus probenecid } \\
500 \mathrm{mg} \text { PO four times daily for } 28 \mathrm{~d}\end{array}$ \\
\hline
\end{tabular}

$\mathrm{MU}$, million units; $\mathrm{PO}$, orally. 
less than $50 \%$ of the cases, and the time lag between the initial exposure and the presentation with arthropathy varied between 5 and 40 years. $^{18,19}$

We believe that this case is the first report of a syphilitic lesion in the cervical spine and the first to present with pure upper motor neuron signs rather than radicular symptoms secondary to mass effect. Previous reported cases documented lesions in the thoracic, thoracolumbar, or lumbar regions, ${ }^{10,12,13,15,20-22}$ and when present, nerve root pain was often nocturnal, persistent, and distressing. ${ }^{19,23}$

The diagnosis of tertiary spinal syphilis is often elusive based on the history, physical examination, and imaging. A key finding is evidence of a previous infection with syphilis. In 1973 and 1985, cauda equina syndrome was described in two male patients as a result of tertiary syphilis. ${ }^{21,24}$ Two further cases were reported in 2009 with vague symptoms of a rash and generalized aches, one suffering a treponemal infection affecting the knees and the elbow and the second with thoracic spinal involvement. ${ }^{25}$ All reported cases, including ours, showed positive nontreponemal (VDRL, RPR) and/or treponemal tests (TPHA, FTA-ABS).

Surgery is a reasonable adjunct to antibiotic therapy for patients suffering compressive neuropathy but care should be taken not to render the affected segment unstable.

\section{Conclusion}

There is a trend of increased prevalence of syphilis in the developed world. This suggests a possibility of an increase in the number of cases presenting with tertiary syphilis. This will create several diagnostic dilemmas and challenges if one is not alert to the possibility of syphilis as a cause particularly in fields where time is critical such as spinal surgery.

\section{Disclosures \\ K. M. I. Salem, None \\ H. Majeed, None \\ R. Bommireddy, None \\ Z. Klezl, None}

\section{References}

1 Righarts AA, Simms I, Wallace L, Solomou M, Fenton KA. Syphilis surveillance and epidemiology in the United Kingdom. Euro Surveill 2004;9:21-25

2 Kent ME, Romanelli F. Reexamining syphilis: an update on epidemiology, clinical manifestations, and management. Ann Pharmacother 2008;42:226-236
3 Schober PC, Gabriel G, White P, Felton WF, Thin RN. How infectious is syphilis? Br J Vener Dis 1983;59:217-219

4 Ho EL, Lukehart SA. Syphilis: using modern approaches to understand an old disease. J Clin Invest 2011;121:4584-4592

5 World Health Organization. The use of rapid syphilis tests, 2006. WHO reference number: WHO/TDR/SDI/06.1

6 Stamm LV. Global challenge of antibiotic-resistant Treponema pallidum. Antimicrob Agents Chemother 2010;54:583-589

7 Lee V, Kinghorn G. Syphilis: an update. Clin Med 2008;8:330-333

8 Kingston M, French P, Goh B, et al; Syphilis Guidelines Revision Group 2008, Clinical Effectiveness Group. UK National Guidelines on the Management of Syphilis 2008. Int J STD AIDS 2008;19: 729-740

9 Lukehart SA, Hook EW III, Baker-Zander SA, Collier AC, Critchlow $\mathrm{CW}$, Handsfield $\mathrm{HH}$. Invasion of the central nervous system by Treponema pallidum: implications for diagnosis and treatment. Ann Intern Med 1988;109:855-862

10 Hannuksela M, Karaharju EO. Syphilis of the spine. Br J Vener Dis 1972;48:397-399

11 Eccleston K, Collins L, Higgins SP. Primary syphilis. Int J STD AIDS 2008;19:145-151

12 Nielsen JP. Follow-up of syphilitics; late manifestations in 467 male patients with early syphilis followed for 29-36 years. Acta Derm Venereol 1950;30:507-512

13 Gjestland T. The Oslo study of untreated syphilis; an epidemiologic investigation of the natural course of the syphilitic infection based upon a re-study of the Boeck-Bruusgaard material. Acta Derm Venereol Suppl (Stockh) 1955;35(Suppl 34):3-368, Annex I-LVI

14 Harrison LW. The Oslo study of untreated syphilis, review and commentary. Br J Vener Dis 1956;32:70-78

15 Johns D. Syphilitic disorders of the spine. Report of two cases. J Bone Joint Surg Br 1970;52:724-731

16 Perkins G. Orthopaedics. London: University of London, The Athlone Press; 1961

17 Park YH, Taylor JA, Szollar SM, Resnick D. Imaging findings in spinal neuroarthropathy. Spine 1994;19:1499-1504

18 Allali F, Rahmouni R, Hajjaj-Hassouni N. Tabetic arthropathy. A report of 43 cases. Clin Rheumatol 2006;25:858-860

19 McNeel DP, Ehni G. Charcot joint of the lumbar spine. J Neurosurg 1969;30:55-61

20 Thomas DF. Vertebral osteoarthropathy of Charcot's disease of the spine. J Bone Joint Surg Br 1952;34-B:248-255

21 Ramani PS, Sengupta RP. Cauda equina compression due to tabetic arthropathy of the spine. J Neurol Neurosurg Psychiatry 1973;36:260-264

22 Natale M, Muras I, Cioffi FA, Bernini FP. Syphilitic spinal arthropathy. Acta Neurochir (Wien) 2001;143:1299-1300

23 Herndon RF. Three cases of tabetic Charcot's spine. J Bone Joint Surg Br 1927;9:605-612

24 Radhakrishnan K, Vijayan VP, Ashok PP, Sridharan R, Mousa ME. Syphilitic spinal neuroarthropathy with paraplegia. Clin Neurol Neurosurg 1985;87:61-64

25 Avenel G, Goëb V, Abboud P, Ait-Abdesselam T, Vittecoq O. Atypical forms of syphilis: two cases. Joint Bone Spine 2009;76: 293-295 